\title{
Technical Efficiency of Smallholder Tomato Production in Semi-Urban Farms in Cameroon: A Stochastic Frontier Production Approach
}

\author{
Martin Paul Jr. Tabe-Ojong ${ }^{1} \&$ Ernest L. Molua ${ }^{2}$ \\ ${ }^{1}$ Institute for Food and Resource Economics, University of Bonn, 53119, Bonn, Germany \\ ${ }^{2}$ Faculty of Agriculture and Veterinary Medicine, University of Buea, Cameroon \\ Correspondence: Ernest L. Molua, Faculty of Agriculture and Veterinary Medicine, University of Buea, \\ Cameroon. E-mail: emolua@cidrcam.org / emolua@gmx.net
}

\author{
Received: July 3, 2017 Accepted: August 18, $2017 \quad$ Online Published: October 25, 2017 \\ doi:10.5539/jms.v7n4p27 URL: http://doi.org/10.5539/jms.v7n4p27
}

\begin{abstract}
Agriculture is the mainstay of Cameroon's economy as it serves the purposes of food, livelihood and employment. Nevertheless, the country's agriculture is plagued by low productivity and inefficiency in production. One of the main reasons for low productivity is the inability of farmers to fully exploit available technologies and production techniques. An important research question that comes to mind is, what are the major factors that hinder the technical efficiency of smallholder farmers? This study thus aimed to determine the level of technical efficiency in the production of tomato in smallholder farms, relying on primary data collected using a structured survey instrument administered to 80 tomato farmers in the Buea municipality of Cameroon. Data was analyzed using descriptive statistics and a stochastic frontier analysis method in the Cobb-Douglas production function. The STATA.14 software was used to obtain both stochastic frontier estimates and the determinants of technical efficiency. The results indicate that farmers are not fully technically efficient with a mean technical efficiency score of 0.68 with one farmer operating on the frontier. The study also revealed that most of the farmers irrespective of the size of the holdings have shown technical inefficiency problems. The older farmers were observed with the best measures of technical efficiency. Education, age and the adoption and practice of agronomic techniques had a positive and significant influence on technical efficiency while the nearest distance to the extension agent had a rather negative influence on technical efficiency. The input-output relationship showed that the area of tomato cultivation and the quantity of improved seed used were positive and significantly related to output at the $5 \%$ level of probability. As a result, it is recommended that farmers should increase their farm size, use of improved seeds and the adoption and practice of novel techniques in production. More emphasis should be placed on extension agents as they have a significant role to play in terms of improving and augmenting farmers' education and information base through on farm demonstrations and result oriented workshops as all this will ensure increased production and productivity thereby increasing technical efficiency and achieving food self-sufficiency.
\end{abstract}

Keywords: Cobb-Douglas production function, technical efficiency, tomato, Cameroon

\section{Introduction}

Cameroon like many other Sub-Saharan African (SSA) countries are still dependent on agriculture for food and livelihood with the exploitation of natural resources remaining the driving force for the country's economic growth and development. Farming is a vital sector involving $80 \%$ of the country's poor and contributing about $30 \%$ of the Gross Domestic Product (GDP) (Molua\&Lambi, 2006). Since independence (1961), the Cameroonian government has made many attempts to improve the productivity of smallholder agriculture in the country. For tomato, this has involved the development of high yielding varieties, subsidization of improved seed varieties and fertilizers, liberalization of tomato prices and product marketing. Despite all these efforts, food security continues to be a problem in Cameroon as is the situation in a number of Sub-Saharan African countries. One important step towards achieving food security could be increasing productivity through enhancing efficiency in production (Wudineh\&Endrias, 2016). In terms of food production, Cameroon is one of the few african countries to have achieved virtual food self-sufficiency and even earns foreign exchange of over 40\% (DSCN, 2002).Attempts are still being made to improve on the agricultural sector in Cameroon (GESP, 2009). 
Tomato (Lycopersion esculentum) is one of the main open field vegetables cultivated and consumed in Cameroon. It has great dietary and economic importance and it is a key input in agro-allied industrial products.Tomato production in Cameroon is estimated at 877,937 tonnes with an accompanying yield level of $12,286 \mathrm{Kg} / \mathrm{ha}$ (Faostat, 2014). This is much lower than the mean world $(33,988 \mathrm{~kg} / \mathrm{ha})$ figures for the same year. Such low yields may be due to the inefficient production level of farmers. Following the Cameroon vision 2035 agenda, which is centred on smallholder agriculture, a lot of concerns and attempts have been made to improve the efficiency of production and productivityof farmers. Improving production efficiency remains a plausible means of increasing productivity when resource reallocation and the creation and adoption of new technologies are limited (Haji \&Andersson, 2006). The Government of Cameroon (GoC) is doing so through the provision of farm inputs, subsidies, improved varieties of crops, construction of farm-to market roads (feeder roads) and the provision of support/ extension services. This is clearly highlighted in the growth and employment strategy paper of the country (GESP, 2009).

One of the main reasons for low productivity in agriculture all over the world, including Cameroon, is the inability of farmers to fully exploit the available technologies and production techniques coupled with limited factors of production which has made it difficult for farmers to uplift production through the use of more inputs (Kavoi et al., 2016). The less than optimal performance of the agricultural sector implies the need for studies to examine the technical efficiency of agricultural production in Cameroon particularly the smallholder tomato farming sector since it involves a good number of households and is vital for food security.

One key to increasing food production in Cameroon lies in raising agricultural productivity through improving the technical efficiency of resource use in agriculture. Productivity entails both technological improvements and technical efficiency (Ogada et al., 2014). Improving the technical efficiency of farmers will lead to an increase in the yield of farmers which will in turn lead to increase in food supply, food security, higher incomes and better standards of living. This may go a long way to reduce the dependence and importation of canned tomatoes as high yields may promote the proliferation of agro-allied industries which will process the tomato fruits. In addition, this will increase the domestic supply which will lead to lower prices in local markets and the potential to export for foreign exchange earnings. However, the main problem here is the existence of very little land to cultivate and improve on the output. Furthermore, the available labour is not well-trained and lack the needed experience to push production to the next level. Finally, there is inadequate institutional support given to tomato farmers coupled with very little access to credits and inputs.

Economists have suggested that there are many factors that influence farmer's efficiency. For instance, Van Passel (2007) broadly summarized these into agent and structural factors. Agent factors are those associated with the farm manager such as educational level, age and social capital. Structural factors are either on- farm (e.g., farm location, farm type, farm size, fertility and drainage) or off-farm such as policy, infrastructure, upstream and downstream relations (Ogada et al., 2014). Different researchers have proxied how the above factors influence technical efficiency. Abebe (2014) pointed out that several empirical studies on productivity and efficiency attribute demographic, socio-economic, institutional and environmental factors to efficiency differentials among farmers (Aigneret al., 1977; Battese\&Coelli, 1995; Bravo-Ureta\&Pinheiro,1997). In the same vein, analyzing the factors that influence the technical efficiency of open tomato production in the Kiambu region of Kenya, Kavoi et al. (2016) found the educational level of the household, experience in tomato farming and family size to have a positive impact on technical efficiency. Expectedly, gender and farm size exhibited a negative relationship. Similarly, in a study in Swaziland, Malinga et al.(2015) established that age, educational level, experience and access to credit had a significant positive relationship on the technical efficiency of tomato growers in the region.

The literature on productive and technical efficiency in Africa is particularly very thin. However, there has recently been emerging research on production and technical efficiency. Despite this, very few studies have profiled the technical efficiency of Cameroon's agriculture despite decades in improving the agricultural productivity of the economy (Binam et al., 2005). For example Ngoe et al.(2016) employing a stochastic production function analyzed the technical efficiency of smallholder cocoa farmers in the Meme division of the Southwest region of Cameroon. They laid emphasis on how the cocoa sector impacts the country's economy socio-economically and found a mean technical efficiency of 0.86 . They found extension services and access to credits as significant determinants of technical efficiency. This was also the case with Binam et al.(2005) who had earlier examined the technical efficiency in smallholder maize and peanut farmers in some selected slash and burn zones of Cameroon and found average technical efficiency levels of 0.79 and 0.80 respectively. They made use of a two stage analysis wherein in the second step, they used a two limit tobit regression technique to assess the relationship between technical efficiency and various farm/farmer characteristics. They found schooling and 
membership in farmer's clubs and associations as crucial sources of technical efficiency, therefore very relevant for policy. To the best of our knowledge, this study will be the first to profile the technical efficiency of tomato farmers in Cameroon and will add to existing literature on technical efficiency by (i) determining the production function of tomato farms, (ii) identifying the factors that influence the technical efficiency of tomato farms (iii) assessing the technical efficiency of the farmers and make recommendations based on the findings of the study.

The rest of the article is structured as follows: The theoretical framework is presented in section 2, followed by the empirical model with data description in section 3. Empirical results and discussion are presented in section 4 .

\section{Theoretical Framework}

The economic theory of production provides the analytical framework for most empirical research on productivity and efficiency (Malinga et al., 2015). Efficiency concerns the relative performance of the processes used in transforming a given input into output (Otieno et al., 2012). Agricultural productivity can be defined as the index of the ratio of the value of total farm output on the value of the total inputs used in the farm production. Since one of the main objectives of any society is the attainment of an optimally high level of living with a given amount of effort, any increase in the productivity of resources employed in farm production will amount to progress. Increasing agricultural productivity will contribute to the well-being of the economy as a whole. From a general perspective, any increase in farm output will result from one of the below mentioned three forces. First it would result from an increased quantity of inputs with no change in output per unit of input. Second, it will result from increased productivity of inputs with no change or a decrease in quantity of input and finally, it will result from a combination of changes in inputs and productivity. This situation makes the concept of efficiency a central issue in production economics (Olayide\& Heady, 1982).

Economic theory distinguishes two measures of efficiency; technical and allocative efficiency. Any firm that achieves both is described as being economically efficient. Several attempts have been made to define economic efficiency and to measure it in an empirical way. Farrel (1957) defined economic efficiency in an admirable and accepted form, but his definition defies precise measurement. His definition of efficiency is couched in three-related terms. Firstly, he defines technical efficiency as the measure of a firm`s success in producing a maximum output from a given set of inputs. It indicates all those undisputed gains that can be obtained by simply gingering up management. Secondly he defines price or allocative efficiency as the measure of a firm's success in choosing an optimal set of inputs. This is an indication of the gains that can be obtained by varying the input ratios on certain assumptions about the future price structure and lastly, he defines overall efficiency as the simple product of the technical and price efficiencies.

The frontier measure of efficiency implies that efficient firms are those operating on the production frontier. The amount by which a firm lies below its production frontier is regarded as the measure of inefficiency (Malinga et al., 2015). Efficiency cannot be easily measured since precise measurements rests on the assumption of an efficient isoquant. However research has established two approaches to measure Efficiency. Farrell (1957) categorized these approaches into parametric and non-parametric measures. The non-parametric approach is a deterministic technique that employs mathematical programming to evaluate relative efficiency. The commonly employed non parametric technique in literature is the Data envelopment analysis which assumes no random mistakes and is mainly used to measure the technical efficiency of decision making units (Fadzima, 2016). Srinivasulu et al.(2015) further opined that the Data envelopment analysis is more appropriate for the industrial, rather than the agricultural sector. The major setback of this approach is its inability to estimate model parameters and allow for hypothesis testing of the fitness of the model (Kavoi et al., 2016). In addition, it does not separately specify efficiency scores from unknown variations (noise). The parametric approach on the otherhand makes use of a stochastic frontier production which is based on the Cobb-Douglas production function incorporated into various estimation methods such as ratio analysis, Ordinary Least Square (OLS), Total Factor Productivity (TFP) and Stochastic Frontier Analysis (SFA) (Fadzima, 2016)

In this study, the stochastic frontier production method was adopted to estimate the technical efficiency of small scale tomato production. This model is appropriate for two reasons: (1) Agricultural production in general depends on climatic conditions and is affected by shocks, hence the need to identify and separate this (Abebe, 2014) and (2) stochastic frontier models specify noise separately from efficiency score and can test hypotheses since a functional form is specified. The outstanding advantage of this model is that it contains an inefficiency component which is used statistically to test for the degree of technical inefficiency of households (Abebe, 2014; Haji \&Andersson, 2006; Malinga et al., 2015; Okoye et al., 2016; Wudineh\&Endrias, 2016) and also less sensitive to outliers (Kavoi et al., 2016). Its main weakness however lies in its assumption of an explicit functional form for technology and frequency for the distribution of the inefficiency terms (Haji \&Andersson, 
The stochastic production frontier was independently proposed by Aigner et al. (1977) and Mueesen \& Broeck (1977). The stochastic frontier model can be generally represented as:

$$
Y_{i}=f\left(X_{i} ; \beta\right) \exp \left(V_{i}-U_{i}\right)
$$

Wherei $=1,2,3 \ldots \ldots \ldots \ldots \ldots, n, X_{i}=$ vector of input quantities used by the $i^{\text {th }}$ farm

$Y_{i}=$ output of the $i^{\text {th }}$ farm, $\beta=$ vector parameters to be estimated, $V_{i}-U_{i}=$ composite error term, $V_{i}$ denotes the random error not under the control of the farmers, assumed to be independently and identically distributed as $\mathrm{N}$ $\left(o, \sigma_{u}^{2}\right)$, independently of $U_{i}$ which is the non-negative random variable associated with technical inefficiency and is identically and independently distributed as atruncated normal, with truncations at zero of the normal distribution (Battesse \& Coelli, 1995).

The technical efficiency (TE) of an individual farm is specified in terms of $\left(\mathrm{Y}^{*}\right)$, conditioned on the level of inputs used by the farm. It is mathematically expressed as $\mathrm{TE}=\mathrm{Y}_{\mathrm{i}} / \mathrm{Y}^{*}$

$$
\begin{gathered}
T E=f\left(X_{i} ; \beta\right) \exp \left(V_{i}-U_{i}\right) \\
f\left(X_{i} ; \beta\right) \exp \left(V_{i}\right) \\
T E=\exp \left(-U_{i}\right)
\end{gathered}
$$

Any farmer who is fully technically efficient will have a value of one and farmers with values lying between zero and below one are said to be technically inefficient.The frontier production function is estimated by the Maximum likelihood estimationtechnique which yield estimators for $\beta$ and $\gamma$, where $\gamma=\sigma_{u}^{2} / \sigma^{2}$ and $\sigma^{2}=\sigma_{u}^{2}+$ $\sigma_{\mathrm{v}}^{2}$. The parameter $\gamma$ represents total variation of output from the frontier that is attributed to technical inefficiency and it lies between zero and one that is $0 \leq \gamma \leq 1$.

\section{Empirical Model}

For the investigation of the technical efficiency and factors affecting the efficiency of smallholder tomato farms in the Buea municipality, a Cobb-Douglas production function was adopted. Despite its well-known limitation, the Cobb-Douglas functional form was used. It has been argued by Binam et al. (2005) that the Cobb-Douglas production function provides an adequate representation of any given production technology. In addition, it is efficient for multiple input modeling and provides an efficient way of handling multicollinearity, heteroscedasticity and correlation (Kavoi et al., 2016). The following Cobb-Douglas stochastic frontier production is specified:

$$
\operatorname{In} Y_{1}=\beta_{o}+\beta_{1} \operatorname{In} X_{1}+\beta_{2} \operatorname{In} X_{2}+\beta_{3} \operatorname{In} X_{3}+\beta_{4} \operatorname{In} X_{4}+V_{i}-U_{i}
$$

Where $\mathrm{Y}$ is the value of tomato output measured in kilograms (kg); $\mathrm{X}_{1}$ is the Farm size (acres), $\mathrm{X}_{2}$ is the fertilizer $(\mathrm{kg}), \mathrm{X}_{3}$ is the seed quantity $(\mathrm{kg}), \mathrm{X}_{4}$ is the totallabour (family and hired) in man days.

The inefficiency model based on Battesse\&Coelli (1995) is specified as

$$
\mathrm{U}_{\mathrm{i}}=\delta_{0}+\delta_{1} \mathrm{Z}_{1}+\delta_{2} \mathrm{Z}_{2}+\delta_{3} \mathrm{Z}_{3}+\delta_{4} \mathrm{Z}_{4}+\delta_{5} \mathrm{Z}_{5}+\delta_{6} \mathrm{Z}_{6}+\delta_{7} \mathrm{Z}_{7}(6)
$$

Where $Z_{1}=$ Gender, $Z_{2}=$ Age, $Z_{3}=$ Education, $Z_{4}=$ Experience, $Z_{5}=$ farm size, $Z_{6}=$ Distance to the nearest extension agent, $Z_{7}=$ Adoption of agronomic techniques. The maximum likelihood estimate of the Cobb-Douglas stochastic frontier production was estimated using the STATA version14.0 software.

\subsection{Data and Study Area}

The study was carried out in the Buea municipality $\left(4^{\circ} 10^{\prime} 0^{\prime \prime} \mathrm{N} 9^{\circ} 14^{\prime} 0^{\prime \prime} \mathrm{E} / 4.16667^{\circ} \mathrm{N} 9.23333^{\circ} \mathrm{E}\right)$ of the Southwest region of Cameroon. The data was obtained from major tomato producing areas of Buea. A multistage sampling procedure was used to purposely select 10 villages based on the intensity of their tomato production. From this, 8 households were randomly selected. In total, 80 households were surveyed with the aid of a Standardised survey instrument. Tomato is a bi-annual open field vegetable crop which thrives well under good moisture conditions. The survey was carried out in the first planting season of the year specifically in May.

\subsection{Description of Variables}

Data was collected on variables ranging from the age of the farmers. Ages were recorded chronologically and not in ranges. The sex of the farmers was treated as dummy, with1 for males and 0 for females. The marital status of the farmers was also treated as a dummy variable with 1 for married and 0 for unmarried farmers. Furthermore, education was captured as the average number of years of schooling for all members of the household. This is because, almost all the members of a household participate in the production of tomato. Labour which comprised both family and hired labour was measured in man days valued at 2000 FCFA (US\$3.5) per man day. Extension 
was tackled as the distance to the nearest extension agent in kilometres. Also the number of years of production of tomato was considered as experience in tomato production. The area under cultivation was measured in acres.The quantity of improved seed used was measured in grams per planted land size. The quantity of fertilizer used was measured in kilograms per acre. Furthermore, the adoption and practice of improved techniques of production was also treated as an indicator variable with 1 representing the practice of agronomic techniques like mulching, weeding, irrigation and soil conservation techniques. The kind of seeds used, the common farming practice, participation in extension activities, income and revenue per production cycle and the problems faced by tomato farmers as well as the possible solutions proposed by the farmers themselves were also taken into consideration.

\section{Results}

The household and socioeconomic characteristics of the various sampled tomato farmers in the Buea municipality are provided in Table 1. According to the survey, the average household had a mean education of 4.22years. The average household education ranged from 0 to 9.25 years portraying that some households had attained no education. This is pretty low and indicative of low education levels among tomato growing households in the Buea municipality. The mean age of the respondents was $45 y$ ears while the mean experience in growing tomatoes was 18 years implying most of the farmers in the study area were very experienced in growing tomatoes. The mean household size was 6persons per family with family labour and hired labour totalling an average of 160 mandays per year. The mean cultivated area employed for tomato production was 4.13 acres which ranged from 0.4 to 12.14 acres. Most of the cultivated areas were borrowed and were usually used for mixed cropping activities. Other vegetable and fruit crops like pepper, green spices, watermelon and even cereals like maize were usually intercropped with tomatoes.

Table 1. Descriptive statistics Tomato farmers in Buea municipality

\begin{tabular}{|c|c|c|c|c|c|}
\hline Variable & Unit & Mean & Std. Dev. & Min & Max \\
\hline \multicolumn{6}{|l|}{ Continuous variable } \\
\hline Total production & $\mathrm{Kg}$ & 1682.875 & 1396.924 & 0 & 6800 \\
\hline Area of cultivation & Acres & 4.136899 & 2.075578 & .4046856 & 12.14057 \\
\hline Household education & Years & 4.223333 & 1.835996 & 0 & 9.25 \\
\hline Age & Years & 45.075 & 6.716266 & 28 & 55 \\
\hline Household size & Number & 5.8375 & 2.101499 & 1 & 11 \\
\hline Experience & Years & 17.95 & 9.891692 & 4 & 40 \\
\hline $\begin{array}{l}\text { Distance to extension } \\
\text { agent }\end{array}$ & $\mathrm{Km}$ & 2.691625 & 2.554745 & 0 & 12 \\
\hline Labour & Mandays & 159.4505 & 142.1483 & 0 & 1133 \\
\hline $\begin{array}{l}\text { Quantity of improved } \\
\text { seed }\end{array}$ & Grams & 129.65 & 107.3398 & 0 & 525 \\
\hline Fertilizer & $\mathrm{Kg}$ & 502.6341 & 330.9054 & 75 & 2400 \\
\hline \multicolumn{6}{|l|}{ Categorical variable } \\
\hline & Label & & & Frequency & Percentage \\
\hline \multirow{2}{*}{ Gender } & Male $=1$ & & & 72 & 90.0 \\
\hline & Female $=0$ & & & 8 & 10.0 \\
\hline \multirow{7}{*}{ Marital status } & Married and living together $=1$ & & & & \\
\hline & Married but separated $=2$ & & & 69 & 86.25 \\
\hline & Divorced/Separated=3 & & & & \\
\hline & Widow/widower=4 & & & 1 & 1.25 \\
\hline & Never married $=5$ & & & 3 & 3.75 \\
\hline & & & & 6 & 7.50 \\
\hline & & & & 1 & 1.25 \\
\hline \multirow{2}{*}{$\begin{array}{l}\text { Adoption of Agronomic } \\
\text { techniques }\end{array}$} & Adopted $=1$ & & & 3 & 3.75 \\
\hline & Not adopted $=0$ & & & 77 & 96.25 \\
\hline
\end{tabular}

Source: Field survey results, 2014.

Very few farmers made use of improved seed varieties which gave a mean improved seed quantity of 130 grams per farm plot. Average fertilizer use per acre of tomato production was $503 \mathrm{~kg}$. The recommended dose for Nitrogen, phosphorus and potassium (NPK) in tomato production are $100 \mathrm{~kg}, 190 \mathrm{~kg}$ and $190 \mathrm{~kg}$ respectively, 
summing up to $480 \mathrm{~kg}$ per acre of NPK (Kavoi et al., 2016). Compared to the mean fertilizer usage in the Buea municipality, farmers used more than the recommended dosage.The mean distance of travel to the nearest extension agent was $2.69 \mathrm{~km}$ and ranged from 0 to $12 \mathrm{~km}$ indicating the presence of extension officers in the study area. With the use of all the mentioned inputs, the mean yield was $1682 \mathrm{~kg}$ of tomatoes harvested per acre.

For the categorical variables, 72 of the respondents were males, giving a percentage of $90 \%$. This clearly shows that tomato production is usually carried out by males. This is justifiable because most of the activities involved are very labour intensive. Adoption was low as only $3.75 \%$ of the farmers adopted and implemented various important tomato growing techniques like irrigation and mulching. Lastly, most of the farmers were married with a high proportion of $87.5 \%$.

\subsection{Stochastic Production Frontier Function}

Table 2 shows the maximum likelihood estimates obtained from the Cobb-Douglas stochastic frontier for tomato production. The study revealed that the quantity of improved seed used and the area of tomato cultivation are important determinants of tomato production. Both variables were positive and statistically significant at the $1 \%$ level of probability. This implies that a percent increase in the quantity of improved seed used and the area of cultivation will increase tomato output by $19.89 \%$ and $92.98 \%$ respectively. This is highly expected and matches with a priori expectations. Furthermore, the coefficient indicates that total output is 5.288 when area of cultivation, fertilizer, improved seed quantity and labour of the farmers are kept constant. The gamma value $(\gamma)$ was 0.973 indicating that $97.3 \%$ of total variation in tomato output is attributed to technical inefficiency.

Table 2. Maximum likelihood estimates of the stochastic production function

\begin{tabular}{|c|c|c|c|c|c|}
\hline Variable & parameters & Coefficients & Std, error & $\mathbf{Z}$ & Pvalue \\
\hline Constant term & $\beta_{\mathrm{o}}$ & $5.288 * * *$ & 1.526 & 3.46 & 0.001 \\
\hline Area of cultivation & $\beta_{1}$ & $0.929 * * *$ & 0.319 & 2.91 & 0.004 \\
\hline Fertiliser & $\beta_{2}$ & 0.129 & 0.285 & 0.45 & 0.650 \\
\hline Seed quantity & $\beta_{3}$ & $0.198 * * *$ & 0.067 & 2.95 & 0.003 \\
\hline Labour & $\beta_{4}$ & -0.013 & 0.105 & -0.13 & 0.897 \\
\hline Insig2v & & $-2.306 * * *$ & & & 0.001 \\
\hline Insig2u & & $1.299 * * *$ & & & 0.000 \\
\hline \multicolumn{6}{|l|}{ Variance parameters } \\
\hline sigma u & & 1.915 & & & 0.000 \\
\hline Sigma v & & 0.315 & & & 0.001 \\
\hline Lambda & & 6.06 & & & \\
\hline Sigma2 & & 3.76 & & & \\
\hline $\operatorname{Gamma}(\gamma)$ & & 0.973 & & & 0.000 \\
\hline LR & & $16.55 * * *$ & & & \\
\hline Log likelihood function & & -119.127 & & & \\
\hline
\end{tabular}

Note. ${ }^{*} \mathrm{p}<0.1 ; * * \mathrm{p}<0.05 ; * * * \mathrm{p}<0.01$. Field survey results, 2014 .

Both sigma $\mathrm{u}\left(\sigma_{\mathrm{u}}\right)$ and sigma $\mathrm{v}\left(\sigma_{\mathrm{v}}\right)$ were statistically significant at the $1 \%$ level of probability, indicating a perfect goodness of fit with the Cobb- Douglas stochastic frontier model as well as the correctness of the specified distributional assumption of the composite error term. The LR test was also significant and less than the critical value implying that the Cobb-Douglas functional form is a better fit to the data than the Trans-log functional form.

\subsection{Factors Influencing Technical Efficiency}

The presence or absence of technical inefficiency was tested in the study using the important parameter of the $\log$ likelihood in the half normal model. If $\lambda=0$, then, there were no effects of technical inefficiency and all deviations from the frontier were due to noise. The estimated value of $\lambda=6.06$ significantly differed from zero. As a result, we fail to reject the null hypothesis that "farmers are technically inefficient" at 0.5 percent level using the z-statistic, suggesting the existence of inefficiency effects for tomato farmers in the Buea municipality. To analyse the factors having an impact on the technical efficiency of tomato production, an inefficiency model was implicitly specified. The estimated factors influencing technical efficiency are presented in Table 3. 
Table 3. Estimated technical efficiency values

\begin{tabular}{llllll}
\hline Variable & Parameter & Coefficient & Std. error & z & P value \\
\hline Constant term & $\delta_{0}$ & $-7.776^{* * *}$ & 2.054 & -3.79 & 0.000 \\
Gender & $\delta_{1}$ & -0.026 & 0.622 & -0.04 & 0.965 \\
Age & $\delta_{2}$ & $0.195^{* * *}$ & 0.431 & 4.54 & 0.000 \\
Education & $\delta_{3}$ & $0.235^{* * *}$ & 0.070 & 3.36 & 0.001 \\
Experience & $\delta_{4}$ & -0.011 & 0.019 & -0.59 & 0.557 \\
Area of cultivation & $\delta_{5}$ & -0.153 & 0.117 & -1.32 & 0.188 \\
Distance to extension agent & $\delta_{6}$ & $-0.195^{* *}$ & 0.099 & -1.96 & 0.05 \\
Adoption of Agronomic techniques & $\delta_{7}$ & $1.529^{*}$ & 0.907 & 1.69 & 0.09 \\
\hline
\end{tabular}

Note. ${ }^{*} \mathrm{p}<0.1 ; * * \mathrm{p}<0.05 ; * * * \mathrm{p}<0.01$. Source: Field survey results, 2014.

The coefficient for age was positive and highly significant at the $1 \%$ level of probability. This implies that the advancement in age leads to an increase in technical efficiency; that older farmers are more technically efficient that their younger counterparts. This positive relationship can be likely attributed to experience in farming as well as frequent contacts with extension agents. Most of the younger farmers may be engaged in other part time activities and secure other livelihood options which reduces their technical efficiency. This result is in line with a similar study on tomato production in Swaziland by Malinga et al.(2015)

Education was proxied as the average household education since farming in the study area involved almost if not all members of the household. It showed a positive relationship with technical efficiency and was significant at the $1 \%$ level of probability. The positive coefficient of education reveals that a high level of education results in increasing the technical efficiency of farmers. This is justifiable as new techniques and innovations are introduced daily especially with the presence of research institutions. Households that are educated will adopt such novel techniques and technologies and increase their technical efficiency. Also educated households will be more exposed to information and will manage their farm production better (Abebe, 2014; Binam et al., 2005; Haji \&Andersson, 2006).

The coefficient of distance to the nearest extension agent was negative and significant at the $5 \%$ level of probability. This implies that the nearer a farmer is to an extension agent, the higher will be his technical efficiency. This is expected as extension agents have been known for their role in smallholder production. They do this through the provision of the latest information on production techniques, provision of improved seeds and provision of agronomic knowledge. The farmer can avail himself of all the above to boast his productivity and technical efficiency.This is confirmed by Ngoe et al.(2016) and Kavoi et al. (2016) in their earlier technical efficiency analysis.

In addition, the coefficient of agronomic techniques used was positive and significant at the 0.1 level of probability, indicating that the more the farmers practice and follow agronomic advice, the more will their technical inefficiency reduce. These agronomic techniques include; mulching, irrigation, and constant weeding. This positive relationship is expected as all these techniques have been proven to both increase productivity and technical efficiency. In Ethiopia, Abebe (2014) proved that the practice of soil conservation had both a positive effect on technical efficiency and in maintaining the environment. Lastly, the coefficients of area of cultivation, experience in tomato production and gender were both negative though not significant.

\subsection{Estimating the Distribution of Technical Efficiency}

The efficiency level of the individual farmers was also estimated with a mean technical efficiency level of $68 \%$. This implies there exists the possibility to increase the technical efficiency level of the farmers in the Buea municipality by $32 \%$ if all the constraints causing inefficiency are improved upon. This mean score is in line with a similar study conducted by Kavoi et al. (2016) who observed a mean technical efficiency level of $65 \%$ amongst tomato growers in the Kiambu region of Kenya. The technical efficiency levels ranged from $0.13 \%$ to $100 \%$, with one farmer being technically efficient. Further analysis revealed that a great majority (57) of the farmers had technical efficiency levels greater than 0.60 . Table 4 presents distribution of technical efficiency amongst the farmers. 
Table 4. Frequency distribution of technical efficiency

\begin{tabular}{lll}
\hline Efficiency level & Frequency & Percentage \\
\hline$\leq 0.20$ & 6 & 7.5 \\
$0.21-0.40$ & 2 & 2.5 \\
$0.41-0.60$ & 15 & 18.75 \\
$0.61-0.80$ & 30 & 37.5 \\
$0.81-1.00$ & 27 & 33.75 \\
Total & 80 & 100 \\
Mean & 0.68 & \\
Standard deviation & 0.24 & \\
Minimum & 0.0013 & \\
Maximum & 1 & \\
\hline
\end{tabular}

Source: Field survey, 2014.

\section{Conclusion}

This study sought to investigate and assess the sources of technical efficiency in smallholder production of tomatoes in the Buea municipality of Cameroon. A Cobb-Douglas production function was specified and an inefficiency model was specified. Maximum likelihood estimates for the parameters of the stochastic production function showed that estimated coefficients of the area of cultivation and quantity of improved seed used were positive and highly significant $(\mathrm{p}<0.01)$. Farmers in the study area had a mean technical efficiency of 68 percent implying there are some existing opportunities to increase the technical efficiency if resources are optimally used and agronomic practices well respected. The determinants of the technical inefficiency model reveal that age and mean household education have a positive significant relationship with technical efficiency. Nearest distance to an extension agent was also observed to have an inverse relationship with technical efficiency while the adoption and practice of various agronomic techniques depicted a positive significant relationship with technical efficiency though at the $10 \%$ level of probability. The study therefore recommends that government and the powers that be significantly put education of the farmers and extension services at the center of agricultural policies. The role of extension agents cannot be over mentioned as they mediate between researchers and the farmers. Education can take the form of specialized trainings, farmer field schools and farmer business schools. The farmers should be encouraged to respect agronomic techniques and adopt novel innovations and farm technologies. The extension agents as vehicles of knowledge and technology transfer should do more on farm demonstrations and result oriented workshops and seminars.

\section{References}

Abebe, G. (2014). Off-farm income and technical efficiency of smallholder farmers in Ethiopia: A stochastic frontier analysis. SLU, Master thesis, no.662.

Aigner, D. J., Lovell, C. K., \& Schmidt, P. (1977). Formulation and Estimation of Stochastic Frontier Production Function Models. Journal of Econometrics, 6(1), 21-37. https://doi.org/10.1016/0304-4076(77)90052-5

Battese, G. E., \& Coelli, T. J. (1995). A model for technical inefficiency effects in a stochastic frontier production function for panel data. Empirical Economics, 20(2), 325-332. https://doi.org/10.1007/BF01205442

Binam, J., Tonye, J., \& Wandji, N. (2005). Source of technical efficiency among smallholder maize and peanut farmers in the slash and burn agriculture zone of Cameroon. Journal of Economic Cooperation, 26, 193-210.

Bravo-Ureta, B. E., \& Pinheiro, A. E. (1993). Efficiency analysis of developing country agriculture: A review of the frontier function literature. Agricultural Resource Economics Review, 22, 88-101. https://doi.org/10.1017/S1068280500000320

DSCN. (2002). Conditions de vie des populations et profil de pauvreté auCameroun en 2001: Premiers résultats, Direction de la Statistique et de la Comptabilité Nationale, Yaoundé-R.C., Mai 2002.

Fadzima, W. R. (2016). Determinants of Technical Efficiency among Smallholder Cocoa Farmers in Malaysia. European proceedings of Social and behavioural sciences ( $\mathrm{pp}$ 688-693). https://doi.org/10.15405/epsbs.2016.08.97

FAO. (Food and Agriculture Organization of the United Nations). (2012). FAOSTAT. Retrieved from http://faostat.fao.org 
Faostat. (2014). Factfish research made simple. Retrieved from $\mathrm{http}: / / \mathrm{www}$. factfish.com/statistic-country/cameroon/tomatoes,+production+quantity

Farrell, M. J. (1957). The measurement of productive efficiency. Journal of Royal Statistical Society, 120, 253-290. https://doi.org/10.2307/2343100

GESP. (2009). Growth and employment strategy, Yaounde, Cameroon.

Haji, J., \& Andersson, H. (2006). Determinants of efficiency of vegetable production in smallholder farms: The case of Ethiopia. Food Economics-ActaAgriculturaeScandinavica, Section C, 3(3-4), 125-137. https://doi.org/10.1080/16507540601127714

Kavoi, M. M., Najjuma, E., \& Mbeche, R. (2016). Assessment of technical efficiency of open field production in Kiambu country, Kenya (Stochastic frontier approach). JAGST, 17(2).

Malinga, N. G., Masuku, M. B., \& Raufu, M. O. (2015). Comparative Analysis of Technical Efficiencies of Smallholder Vegetable Farmers with and Without Credit Access in Swazil and the Case of the Hhohho Region. International Journal of Sustainable Agricultural Research, 2(4), 133-145. https://doi.org/10.18488/journal.70/2015.2.4/70.4.133.145

Meeusen, W., \& van den Broeck, J. (1977). Efficiency estimation from Cobb-Douglas production functions with composed errors. International Economic Review, 18, 435-444. https://doi.org/10.2307/2525757

Molua, E. L., \& Lambi, C. M. (2006). Assessing the impact of climate on crop water use and crop water productivity: The CROPWAT analysis of three districts in Cameroon. CEEPA Discussion Paper No. 33, Centre for Environmental Economics and Policy in Africa, University of Pretoria.

Ngoe, M., Jing, Z., Mukete, B., Tabi, G., Kimengsi, J., \& Aniah, D. (2016). Analysis of the Technical Efficiency of Smallholder cocoa farmers in Southwest Cameroon. AmericalJournal of Rural Development, 4, 129-133.

Ogada, M. J., Muchai, D., Mwabu, G., \& Mathenge, M. (2014). Technical efficiency of Kenya's smallholder food crop farmers: Do environmental factors matter? Environment, Development and Sustainability, 16(5), 1065-1076. https://doi.org/10.1007/s10668-014-9513-1

Okoye, B. C., Abass, A., Bachwenkizi, B., Asumugha, G., Alenkhe, B., Ranaivoson, R., ... Elliott, C. (2016). Differentials in technical efficiency among smallholder cassava farmers in Central Madagascar: A Cobb Douglas stochastic frontier production approach. Cogent Economics and Finance, 4(1), 568. https://doi.org/10.1080/23322039.2016.1143345

Olayide, S. O., \& Heady, E. O. (1982). Introduction to agricultural production economics. Ibadan: University of Ibadan press Nigeria. Chapters 2,3 and 7.

Otieno, D. J., Hubbard, L., \& Ruto, E. (2012). Determinants of technical efficiency in beef cattle production in Kenya. [Paper Presented at Triennial Conference of International Association of Agricultural Economists (IAAE), Foz du Iguacu, Brazil, 18-24 August, 2012]

Srinivasulu, R., Victor, A. S., Daniel, K. K., Richard, M., Dannie, R., Magesa, A. M., ... Radegunda, F. K. (2015). Technical efficiency of traditional African vegetable production: A case study of smallholders in Tanzania. Journal of Development and Agricultural Economics, 7(3), 92-99. https://doi.org/10.5897/JDAE2014.0606

Van Passel, S., Louwers, L., \& Van Huylenbroeck, G. (2006). Factors of farm performance: An empirical analysis of structural and managerial characteristics. New York: Nova Science Publishers

Wudineh, G. T., \& Endrias, G. (2016). Technical efficiency of smallholder wheat farmers: The case of Welmera district, Central Oromia, Ethiopia. Journal of Development and Agricultural Economics, 8(2), 39-51. https://doi.org/10.5897/JDAE2015.0660

\section{Copyrights}

Copyright for this article is retained by the author(s), with first publication rights granted to the journal.

This is an open-access article distributed under the terms and conditions of the Creative Commons Attribution license (http://creativecommons.org/licenses/by/4.0/). 